Int. J. Dev. Biol. 49: 843-850 (2005)

doi: $10.1387 / \mathrm{ijdb} .052027 \mathrm{so}$

Original Article

\title{
The formation of primordial germ cells from germline cells in spherical embryos derived from the blastodisc of 2-cell em- bryos in goldfish, Carassius auratus
}

\author{
SATOSHI OTANI',4, TOMOE KITAUCHI', TAIJU SAITO1, SUZU SAKAO ${ }^{1}$, SHINGO MAEGAWA ${ }^{3}$, \\ KUNIO INOUE ${ }^{3}$, KATSUTOSHI ARAI ${ }^{1}$ and ETSURO YAMAHA ${ }^{*}, 2,4$ \\ ${ }^{1}$ Laboratory of Breeding Science, ${ }^{2}$ Laboratory of Cellular Information Science, Graduate School of Fisheries Sciences, Hokkaido University, \\ Hakodate, Japan, ${ }^{3}$ Molecular and Developmental Biology, Graduate School of Biological Sciences, Nara Institute of Science and Technol- \\ ogy, Ikoma, Japan and ${ }^{4}$ Nanae Fresh Water Laboratory, Field Science Center for Northern Biosphere, Hokkaido University, Nanae, Japan.
}

\begin{abstract}
The property of primordial germ cells (PGCs) in fragmented goldfish embryos was investigated. When 1- and 2- cell embryos were cut at several perpendicular levels at the animalvegetal axis, cells expressing vas mRNA were observed in the resultant embryos derived from all kinds of animal fragments. Blastodisc fragments from the 1- to 2-cell stage developed to spherical embryos containing yolk body with a yolk syncytial layer (YSL). Germ ring and no tail expression were not observed in the spherical embryo. When the spherical embryo labeled with tracer dye or GFP-nos 1 3'UTR mRNA was transplanted onto the animal part of the blastoderm in a host embryo at the blastula stage, PGCs of spherical embryo origin were detected around the gonadal ridges in the resultant embryos which developed normally. These results suggest that small animal fragments should contain factors sufficient for PGC differentiation and that PGCs differentiate without mesoderm induction, since mesoderm is not induced in a spherical embryo.
\end{abstract}

KEY WORDS: goldfish, PGCs, vas, nanos, maternal cytoplasmic component

\section{Introduction}

Primordial germ cells (PGCs), the precusor of germ cells, differentiate during early development by predetermination or induction. PGCs that arise early in development are morphologically distinct from somatic cells and actively migrate from their place of emergence to the gonadal anlage (reviewed by Nieuwkoop and Sutasurya, 1976; Timmermans, 1996; Coffman, 2003). Therefore, PGCs have provided an intriguing model system for developmental studies on cell determination and migration.

In Drosophila, Caenorhabditis elegans and Xenopus laevis, PGCs are formed from cells with maternally synthesized cytoplasm, which are thought to contain germ cell determinants (reviewed by Stanz-Gaiano and Lehmann, 2001). In Drosophila in particular, a few components, such as vasa, nanos (nos), polar granule component (pgc) and scattershot (sctt), have been identified in the cytoplasm (Stanz-Gaiano and Lehmann, 2001; Coffman, 2003). Nos is one of the maternal proteins known to direct regulate zygotic vasa expression autonomously in the germ-line progenitors (Sano et al., 2001) and to repress the expression of somatic genes (Hayashi et al., 2004).
In contrast, it has been suggested that the specification of PGCs in the mammalian embryo does not depend on maternal determinants. Mesoderm-inducible signals affect the differentiation of germline lineage from surrounding somatic cells (Lawson et al., 1999). Additionally, in other animals, PGCs seem to relate closely to surrounding tissues, especially the mesoderm, in the process of differentiation and migration to the genital anlage. In urodeles, it has been reported that PGCs are induced through mesoderm formation (Sutasurya and Nieuwkoop, 1974). It has also been reported that the presumptive germ cells in Drosophila are closely associated with the posterior midgut primordium during migration (Jaglarz and Howard, 1994).

In teleosts, some maternal mRNAs, such as vasa and nanos homologues (vas and nos1), have been identified and found to move to the animal pole region by means of axial streamers during blastodisc formation (reviewed by Pelegri, 2003). Furthermore, they are located at the terminal regions of early cleavage furrows as subcellular clumps and are inherited to the

Abbreviations used in this paper: DAB, diaminobenzidine; GFP, green fluorescent protein; PGCs, Primordial germ cells; UTR, untranslated region; WMISH, whole mount in situ hybridization; YSL, yolk syncytial layer.

*Address correspondence to: Dr. Etsuro Yamaha. Nanae Fresh Water Laboratory, Field Science Center for Northern Biosphere, Hokkaido University, Nanae, 041-1105, Japan. Fax: +81-138-65-2237. e-mail: eyamaha@fsc.hokudai.ac.jp 

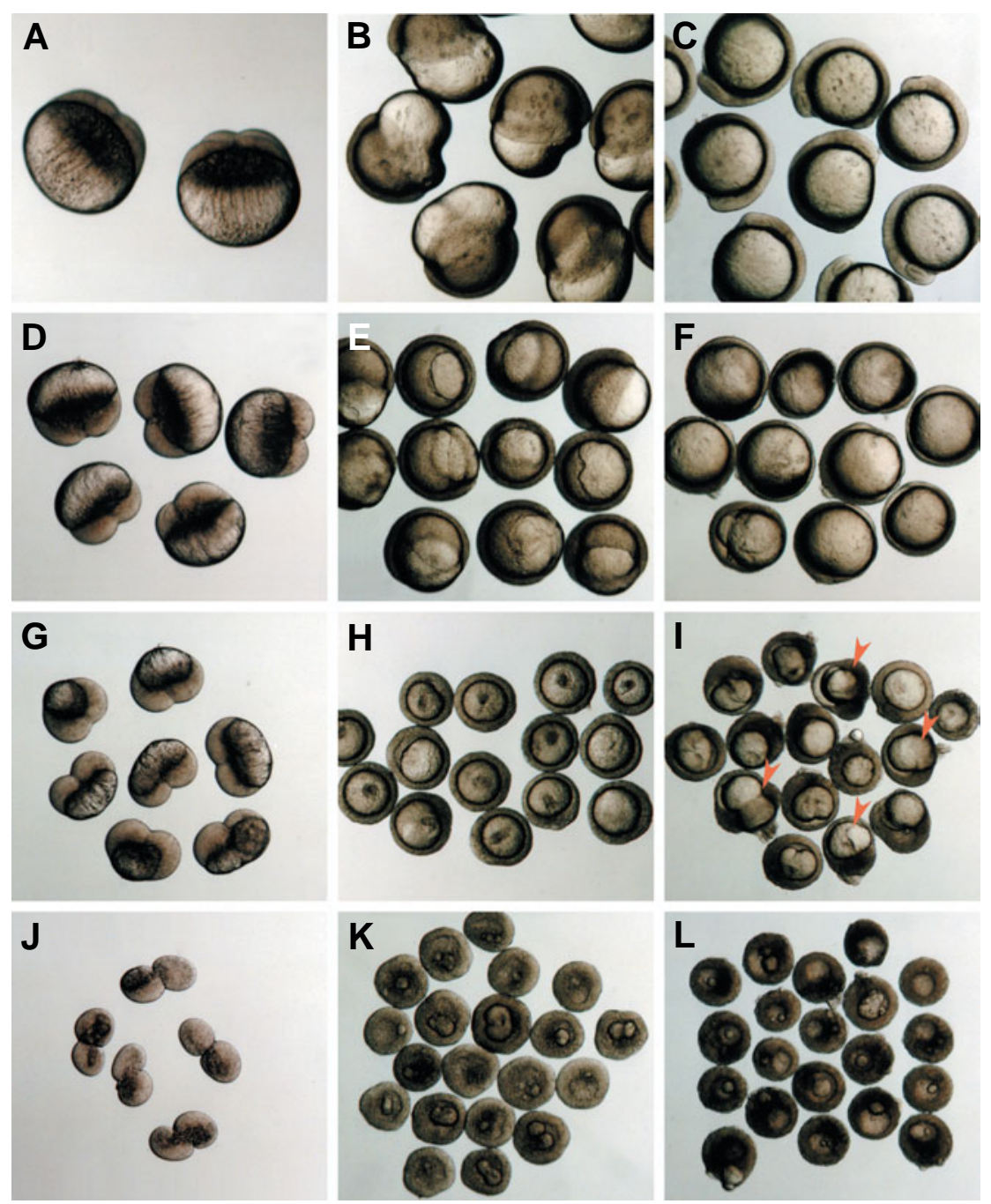

Fig. 1. Development of fragmented eggs. (A-C) Control embryos. (D-F) Fragmented embryos at the half level perpendicular to the animal-vegetal axis at the 1-cell stage (1/2 fragments). (G-I) Fragmented embryos at the one-third level perpendicular to the animalvegetal axis at the 1-cell stage (1/3 fragments). (J-L) Fragmented blastodiscs at the 2-cell stage (2-cell fragments). Fragmented and control embryos at the 2-cell stage $(A, D, G, J)$, at $14 \mathrm{hpf}(B, E, H, K)$ and at $25 \mathrm{hpf}(C, F, J, L)$. Arrowheads in (I) indicate embryos with a germ ring. formation might require close contact with mesoand/or endoderm cells (Braat et al., 1999) even though some PGCs have occasionally been observed out of the mesodermal region at the blastula stage (Otani et al., 2002; Saito et al., 2004). Nevertheless, it remains uncertain in teleosts whether mesoderm induction affects the differentiation of $P G C$ during these stages or not.

In order to elucidate the influence from the mesoderm, it is necessary to investigate the behavior of PGC in the embryo without mesoderm. Fragmentation of fish eggs has been carried out in Fundulus (Oppenheimer, 1936) and goldfish (Tung et al., 1945). In these studies, a spherical embryo (or hyperblastula) without any special structures was described in the resultant embryos from isolated blastodisc and egg fragments. Furthermore an animal hemisphere develops a rotationally symmetrical embryo without gsc expression, responsible for dorsal mesoderm formation, after the vegetal hemisphere is horizontally removed at the early cleavage stage in zebrafish and goldfish (Mizuno et al., 1997, 1999). The results concerning the animal hemisphere suggest that dorsal determinant(s) should redistribute from the vegetal to the animal hemisphere, and the existence of the spherical embryo suggests that the absence of mesoderm is caused by the fragmentation of the activating fish embryo. It is known that, during egg activation, the cortically localized mRNAs such as vasa become enriched at the boundary between the blastodisc and the yolk cell, possibly through movements along the cortex. At the same time, vegetally localized and uniformly distributed mRNAs, including activin receptor type $/ /, \beta$-catenin and goosecoid, are translocated to the forming blastodisc by means of axial streamers (reviewed by Pelegri, 2003).

In the present study, we show that PGCs in the egg fragment without mesoderm induction future germ cells (Yoon et al., 1997; Köprunner et al., 2001; Otani et al., 2002; Saito et al., 2004). In zebrafish, when the region in which maternal mRNAs are located is surgically removed during early cleavage stages, PGCs do not form in the resultant embryo, suggesting the predetermination of PGCs (Hashimoto et al., 2004).

Nevertheless, it remains unclear whether or not the assembly of maternal mRNAs is sufficient in teleosts to form functional PGCs. Presumptive PGCs or PGCs locate around the blastoderm margin, which is thought to be highly significant because many early genes, such as no tail ( $n t$ l, Schulte-Merker et al., 1992), axial (Strähle et al., 1993), eve1 (Joly et al., 1993), goosecoid (gsc, Stachel et al., 1993), lim1 (Toyama et al., 1995) and gata5 (Rodaway et al., 1999), are expressed in this region during meso- and endoderm formation at the lateblastula to shield stage. Therefore, it is thought that PGC maintain the expression of vas and the migrating activity to the gonadal anlage.

\section{Results}

The development of control embryos and animal-part fragments is shown in Fig. 1. When the 1-cell embryo was fragmented horizontally to two equal parts, the resultant animal parts (1/2 fragments: Fig. 1D) developed to dorsal-deficient embryos at 25 hpf (Fig. 1F), as described previously in Mizuno et al. (1997). At 15 hpf, a germ ring had formed, but not an embryonic shield (Fig. 1E). Histologically, a yolk syncytial layer (YSL) was observed on the yolk (data not shown).

In $1 / 3$ fragments (Fig. 1G), animal fragments developed to spherical embryos, containing a yolk body, by $15 \mathrm{hpf}(\mathrm{Fig} .1 \mathrm{H})$. The

\section{Development of animal-part fragments}


surface of the yolk body was histologically covered with YSL (data not shown). At $25 \mathrm{hpf}$, a small number of fragments formed a germ ring and the others maintained the spherical shape of the embryo (Fig. 1I).

The development of 2-cell fragments is shown in Figs. $1 \mathrm{~J}$-L and 3. Fragments at the 2-cell stage contained a small yolk in the cytoplasm just after operation (Fig. 1J). The fragment of the animal side subsequently cleaved after fragmentation. The cleavage furrow in the fragment was not always complete and blastomeres were occasionally connected through a small yolk body. After operation, the vegetal fragment showed the formation of an additional blastodisc (Fig. 2A) which was smaller than the blastodisc of the homochronous unfertilized egg (Fig. 2B). At 6 hpf, when control embryos were at the blastula stage (Fig. 2B), the fragment developed to a spherical embryo, containing a yolk body or bodies inside it, (Fig. 2C). Histologically, the yolk body was covered with YSL at $8 \mathrm{hpf}$ (Fig. 2 D,E). At $15 \mathrm{hpf}$, when control embryos were at the early gastrula stage (Fig. 1B), no germ ring was formed in spherical embryos derived from 2-cell fragments (Fig. 1K). At 25 hpf, when controls were in the early segmentation period (Fig. 1C), a large blastocoel with a yolk body was also observed in the spherical embryos (Fig. 1L).

In spherical embryos derived from $1 / 3$ and 2-cell fragments, no germ ring was formed, suggesting that the mesoderm was not induced. Therefore, $n t /$ expression was examined in fragmented embryos by in situ hybridization at 15 and $22 \mathrm{hpf}$ (Table 1). $n t /$ signals were detected in embryos from all control and $1 / 2$ fragments, but not detected in any 2 -cell fragments. In the case of the resultant embryos from 1/3 fragments, partial $n t /$ signals were observed in about half of the samples, but no signals were detected in the rest. Thus, it is considered that the mesoderm did not differentiate in the 2-cell fragments.

\section{vas-positive cells in animal-part fragments}

Aggregations of vas mRNA were detected along the ends of cleavage furrows close to yolk (Fig. 3) in 4-cell embryos derived from blastodisc fragments at the 1-cell stage. Some signals were located along the marginal area between blastomeres and the yolk body.

vas-positive cells were observed in resultant embryos derived
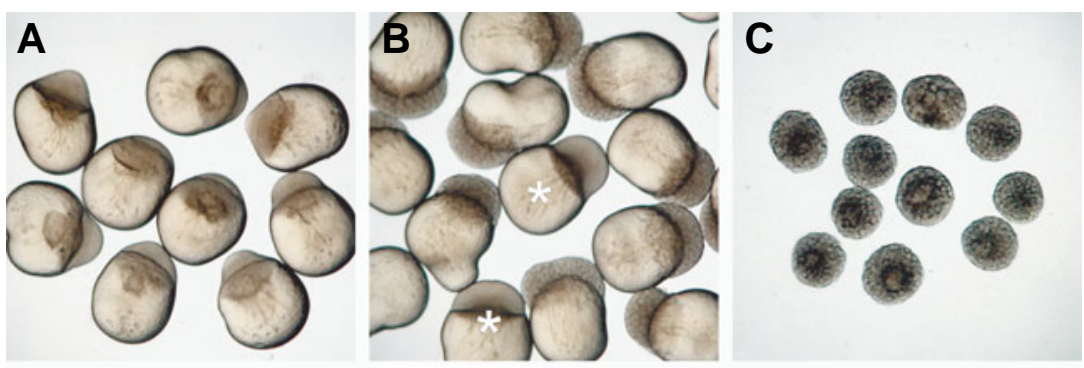

D

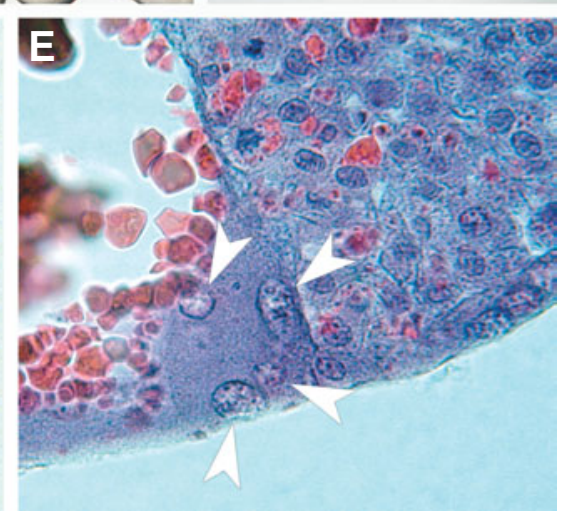

Fig. 2. External appearance and histological profiles of spherical embryos. (A) Vegetal yolk at $6 \mathrm{~h}$ after fragmentation of the blastodisc. (B) Host embryos at 6 hpf. Asterisk (*) indicates unfertilized eggs (cf. vegetal yolk). (C) Spherical embryos at 6 hpf (D) Section of a spherical embryo at $8 \mathrm{hpf}$, when the control embryo was at the lateblastula stage. (E) Higher magnification of (D). Many nuclei were observed in the YSL surface of the yolk body (arrowheads).
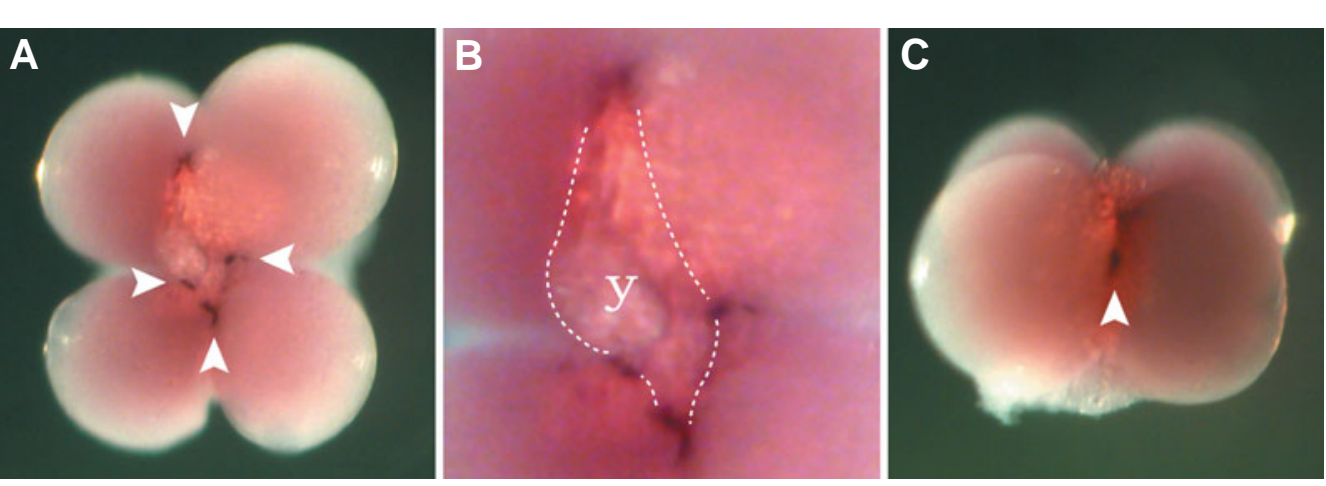

from all the types of fragmentation by WM-ISH (Fig. 4). At $14 \mathrm{hpf}$, when the control embryos showed $30 \%$ epiboly (Fig. $4 \mathrm{~A}$ ), vaspositive cells in embryos from 1/2 fragment were detected in the lower part of the blastoderm, especially inside of the mesendodermal region with $n t /$ expression, but a few vas -signals were occasionally observed out of the region (Fig. 4C). At 25 hpf, when the controls were $100 \%$ epiboly, alignment of vas-positive cells were detected at vegetal part of embryo (Fig. 4D). In these embryos, no dorsal structures were observed.

In spherical embryos from $1 / 3$ and 2-cell fragments at 14 and 25 hpf, vas-positive cells were also detected (Fig. 4 E-H). Although the precise number of vas-positive cells was not counted, over 8 cells were observed at $14 \mathrm{hpf}$.

\section{PGCs from the 2-cell fragment}

In order to elucidate whether vas-positive cells in spherical 
embryos from the 2-cell fragments exhibit migration activity to the gonadal anlage, spherical embryos were transplanted to the host. When the control embryos were at the mid-blastula stage, spherical embryo labeled with biotin- and FITC-dextran or GFP-nos1 3'UTR mRNA were halved without disruption of the inner yolk and transplanted onto the animal part of the host embryo (Figs. 6 A,A'). Transplanted blastomeres were distributed around the animal part of the chimeric embryos at $50 \%$ epiboly, when the germ ring formed (Fig. 5B') and in the head region at the 9-11 somite stage (Fig. 5C'). The inner yolk body, together with embryonic cells in the spherical embryo, was transplanted into a host blastoderm. The yolk body was found in anywhere, such as the head, trunk and yolk sac, of each embryo transplanted at $30 \mathrm{hpf}$ (Fig. 5 B,C). No special structure or histological disorders were found in the vicinity of the yolk body (Fig. 6A). Distinct YSL around the yolk body were observed (Fig. 6B).

When the spherical embryo labeled with GFP-nos 1 3'UTR mRNA was transplanted, donor PGCs with bright green fluorescence and somatic cells with pale fluorescence were observed in the chimeric embryos (Fig. 7). Bright cells considered to be
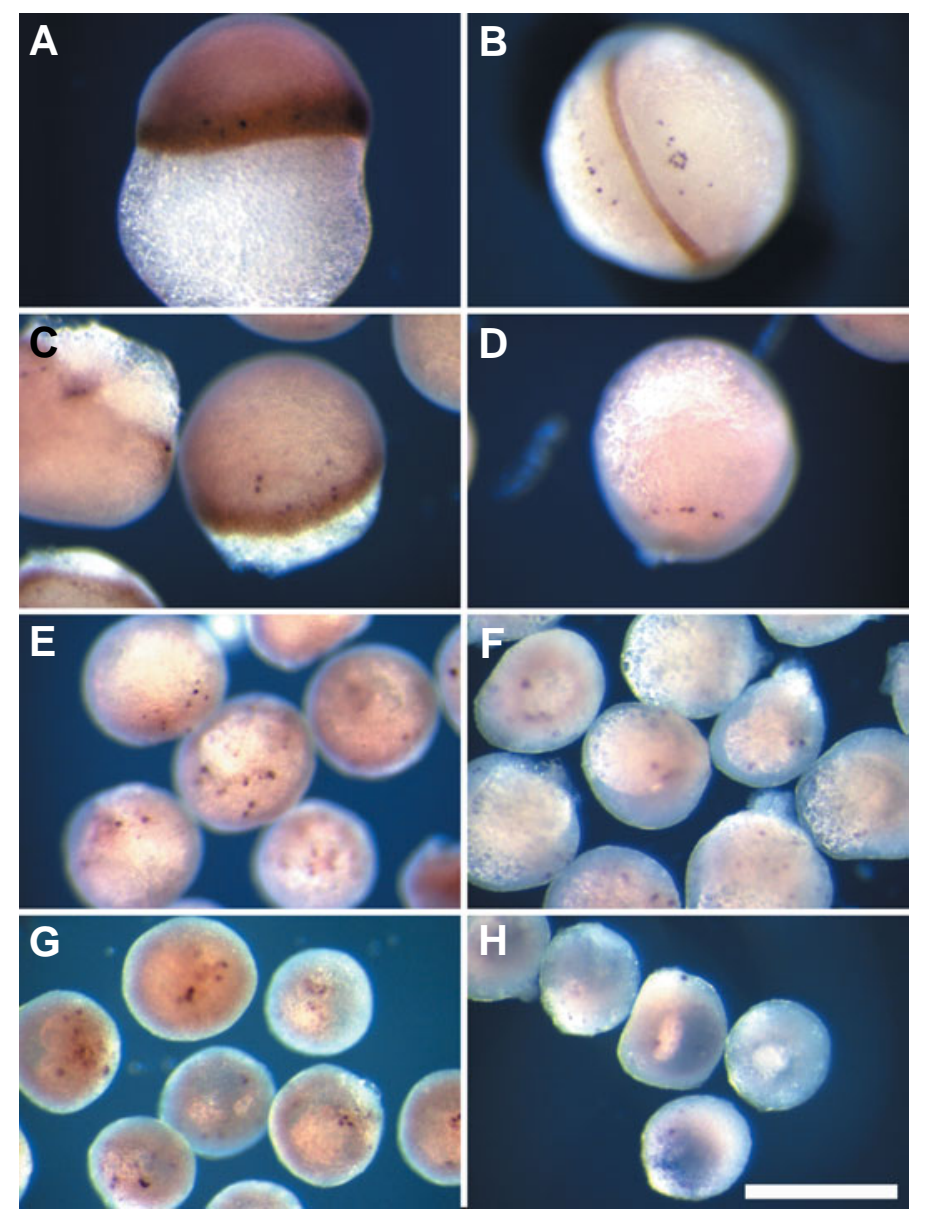

Fig. 4. Distribution of PGCs indicated by vas signals in fragmented and control embryos. (A,B) Control embryo. (C,D) 1/2 fragments. (E,F) 1/3 fragments. (G,H) 2-cell fragments. (A,C,E and G) Embryos at $14 \mathrm{hpf}$. $(B, D, F$ and H) Embryos at 25 hpf. Signals in purple indicatevas, while those in brown indicate ntl. Scale bar, $500 \mu \mathrm{m}$.
TABLE 1

\section{STRENGTH OF NO TAIL SIGNAL AT 15 OR $22 \mathrm{H}$ POST-FERTILIZATION IN EGG FRAGMENT}

\begin{tabular}{|c|c|c|c|c|c|c|c|c|}
\hline \multirow[t]{2}{*}{ Operation } & \multirow{2}{*}{\multicolumn{2}{|c|}{ Time $\left(\right.$ hpf $\left.^{\star}\right)$ Total no. }} & \multicolumn{6}{|c|}{ no tail signal } \\
\hline & & & Normal & (\%) & Partial & (\%) & None & $(\%)$ \\
\hline \multirow[t]{2}{*}{ Denuded control } & 15 & 8 & 7 & $(87.5)$ & 1 & $(12.5)$ & 0 & $(0.0)$ \\
\hline & 22 & 31 & 30 & $(96.8)$ & 1 & (3.2) & 0 & $(0.0)$ \\
\hline \multirow[t]{2}{*}{$1 / 2$ fragment } & 15 & 6 & 4 & $(66.7)$ & 2 & (33.3) & 0 & $(0.0)$ \\
\hline & 22 & 4 & 3 & $(75.0)$ & 1 & $(25.0)$ & 0 & $(0.0)$ \\
\hline \multirow[t]{2}{*}{$1 / 3$ fragment } & 15 & 9 & 0 & $(0.0)$ & 4 & $(44.4)$ & 5 & $(56)$ \\
\hline & 22 & 13 & 0 & $(0.0)$ & 5 & $(38.5)$ & 8 & (62) \\
\hline 2-cell fragment & 15 & 7 & 0 & $(0.0)$ & 0 & $(0.0)$ & 7 & $(100)$ \\
\hline- & 22 & 10 & 0 & $(0.0)$ & 0 & $(0.0)$ & 10 & (100) \\
\hline
\end{tabular}

TABLE 2

\section{NUMBER OF BIOTIN-LABELED PGCS DERIVED FROM DONOR SPHERICAL EMBRYO IN EACH TRANSPLANTED EMBRYO AT 10 DAYS AFTER OPERATION}

\begin{tabular}{lccccccccc} 
Individual no. & \# 1 & $\mathbf{\# ~ 2}$ & $\mathbf{\# ~ 3}$ & $\mathbf{\# ~ 4}$ & $\mathbf{\# ~ 5}$ & $\mathbf{\# ~ 6}$ & $\mathbf{\# ~ 7}$ & \# 8 & Average \\
\hline Total no. of PGCs & 25 & 15 & 23 & 27 & 32 & 37 & 45 & 30 & 29.3 \\
Biotin-labeled PGCs & 3 & 6 & 10 & 10 & 12 & 17 & 19 & 22 & 12.4 \\
$(\%)$ & $(12.0)$ & $(40.0)$ & $(43.5)$ & $(37.0)$ & $(37.5)$ & $(45.9)$ & $(42.2)$ & $(73.3)$ & $(42.3)$ \\
\hline
\end{tabular}

PGCs appeared at the early segmentation period and were observed at the head region forming two clusters and along both sides of the embryonic body, forming lines (Fig. 7 B, B'). Thereafter, anterior clusters of bright cells were identified around the head region anterior to the otic vesicle at $4 \mathrm{dpf}$, while posterior lines moved to more posterior regions (Fig. 7 C, C').

In the resultant larvaes at $10 \mathrm{dpf}$ after transplantation, the biotin-labeled cells derived from the spherical embryos were mainly detected around the head region and several labeled cells were distributed in many parts of the larval body (data not shown). PGCs in the chimeric larvaes $(n=8)$ were identified around the gonadal anlage by histological analysis and some labeled PGCs also were detected (Fig. 8 A,B; Table 2).

\section{Discussion}

\section{Mesoderm differentiation in egg fragments}

Spherical embryos derived from blastodisc fragments at the 2-cell stage consisted of blastoderm cells and a yolk body with a YSL, but showed no special structures or $n t /$ expression. And most resultant embryos after the transplantation of spherical embryos developed normally, in spite of the existence of a yolk body from the donor. $n t /$ is expressed transiently throughout the presumptive mesoderm induced by yolk cell-derived TGF-beta family signals and regulates or interacts with the genes which play essential roles in the development of midline structures. (reviewed by Hoffmann and Valencia, 2004). In fact, a transplanted yolk cell from a normal embryo at the blastula stage has a potential to induce the ectopic expression of mesodermal genes such as $g s c$ and $n t /$ in the host blastomeres adjacent to the donor YSL (Mizuno et al., 1996) and mesodermal cells transplanted from a germ ring onto the animal part of the blastoderm at the same stage perturb the anteroposterior axis at the head region of the resultant embryo (Woo and Fraser, 

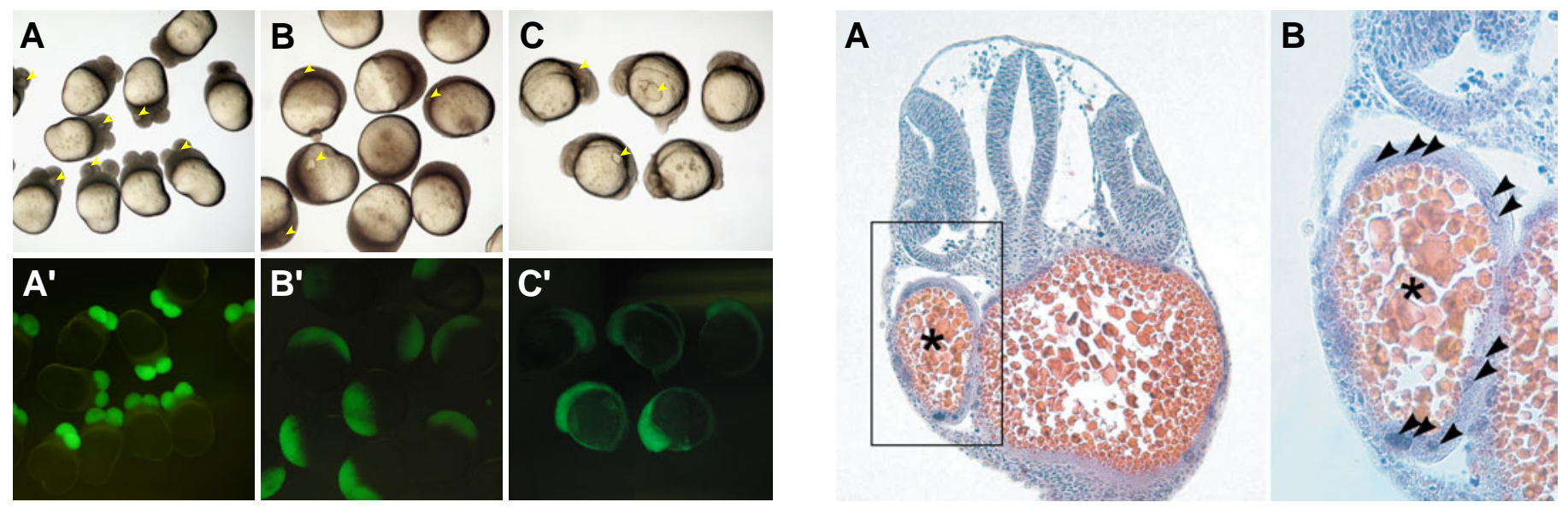

Fig. 5 (Left). Transplantation of spherical embryos and the development of resultant embryos. (A) Transplanted embryos with spherical embryos at $2 \mathrm{~h}$ after operation (8 hpf). Arrowheads indicate yolk bodies derived from spherical embryos. (B) Transplanted embryos at $8 \mathrm{~h}$ after operation (14 hpf). (C) Transplanted embryos at $24 \mathrm{~h}$ after operation (30 hpf). (A', $\left.\mathbf{B}^{\prime}, \mathbf{C}^{\prime}\right)$ indicate fluorescence views of (A, B and C), respectively. Cells derived from spherical embryos are shown with green fluorescence from FITC.

Fig. 6 (Right). Yolk body from a spherical embryo at $\mathbf{3 0} \mathrm{h}$ after transplantation (36 hpf) onto the host embryo at the blastula stage. (B) Higher magnification of (A). Asterisk $\left({ }^{*}\right)$ indicates the yolk body derived from the spherical embryo. Arrowheads indicate the nuclei of the YSL.

1997). So these data suggest that the YSL of the yolk body from the spherical embryo has no potential to induce the mesoderm.

The embryo of animal hemisphere (1/2 fragment in this study) develops a rotationally symmetrical embryo without $g s c$ expression, but maintains $n t /$-inducing activity (Koshida et al., 1998, Mizuno et al., 1999). In the present results, the spherical embryos from $1 / 3$ and 2-cell fragments allow speculation that mesodermal determinants might localize widely around vegetal region in the yolk cell, like $\mathrm{Vg} 1$ and $\mathrm{Veg} \mathrm{T}$ in Xenopus (Agius et al., 2000). Nevertheless, it remains unknown whether $n t /$ induction is responsible for downstream process of determinative molecules supplied maternally. More detailed study, such as transplantation of cytoplasm from vegetal fragments, will be required in the near future.

\section{PGC determination in fragmented embryos}

In the blastodisc fragments at the 1-cell stage, vas mRNA signals were observed at subsequent cleavage furrows. vas-positive cells were detected even in the spherical embryos from 2-cell fragments. Moreover, some PGCs from donor spherical embryos migrate to the gonadal anlage through proper routes in chimeric embryos. Therefore, we conclude that the requisite factors for PGC differentiation are included even in the blastodisc at the 2-cell stage.

In teleosts, the relationships between PGCs and surrounding tissues, especially the YSL, have been previously discussed (Braat et al., 1999). In goldfish, however, presumptive PGCs are frequently detected outside of presumptive mesendoderm area where $n t /$ expresses, suggesting that PGCs differentiate independently without the mesendoderm during early gastrulation (Otani et al., 2002). In the present study, vas signals were detected until $30 \mathrm{hpf}$ in spherical embryos without a mesoderm. Moreover, donor PGCs were detected at the gonadal anlage, even when the spherical embryo was transplanted onto the prospective ectoderm region of the host embryo. These results suggest that PGCs differentiate without signals of mesoderm induction at least during the blastula stage. It remains unknown at present whether the YSL affects PGC differentiation after gastrulation.

When spherical embryo labeled with GFP-nos 1 3'UTR were
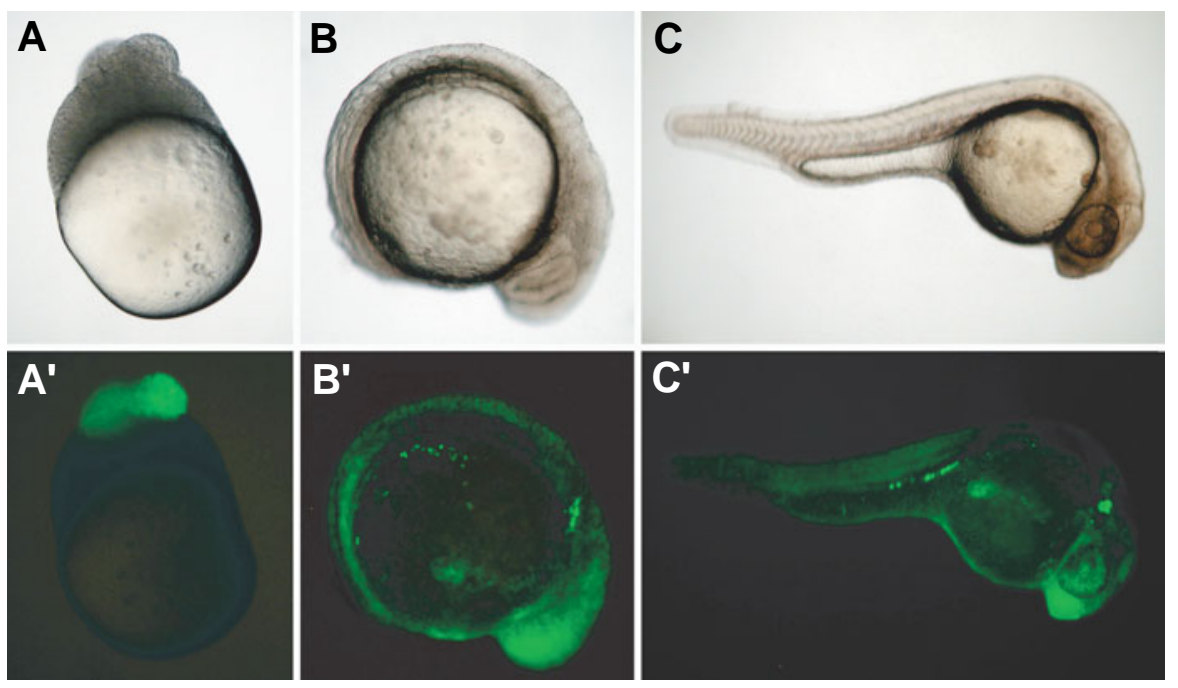

Fig. 7. Distribution and migration of PGCs derived from spherical embryos injected with GFP-nos 13 'UTR mRNA and transplanted onto a host animal pole region. (A) Transplanted embryo at approximately about $2 \mathrm{~h}$ after operation. (B) Transplanted embryo at $30 \mathrm{~h}$ after operation (36 hpf). (C) Transplanted embryo at $3 \mathrm{dpf}$. (A, B,C) show different stages of a single embryo. ( $\left.\mathbf{A}^{\prime}, \mathbf{B}^{\prime}, \mathbf{C}^{\prime}\right)$ indicate fluorescence views of $(A, B, C)$, respectively. Groups of PGCs with bright fluorescence are observed around the trunk and head region in $\left(B^{\prime}\right)$ and $\left(C^{\prime}\right)$. 



Fig. 8. Histological section indicating PGCs derived from spherical embryos. (A) A section of a transplanted embryo at $10 \mathrm{dpf}$. (B) Higher magnification of the rectangles in (A). Cells with a brown color indicate PGCs (arrowhead).

transplanted onto the animal part of the host blastoderm, labeled PGCs were observed not only bilateral region of the trunk, but also around head region. PGCs are rarely observed around the head region in zebrafish after the segmentation period, although they are frequently observed in this position in goldfish (Weidinger et al., 1999; Otani et al., 2002). It is thought that the ectopic distribution of PGCs around the head is caused by widespread mixing of blastomeres from the marginal region to the animal region of the blastoderm during the blastula to epiboly stage in goldfish (Otani et al., 2002). The present results may support this
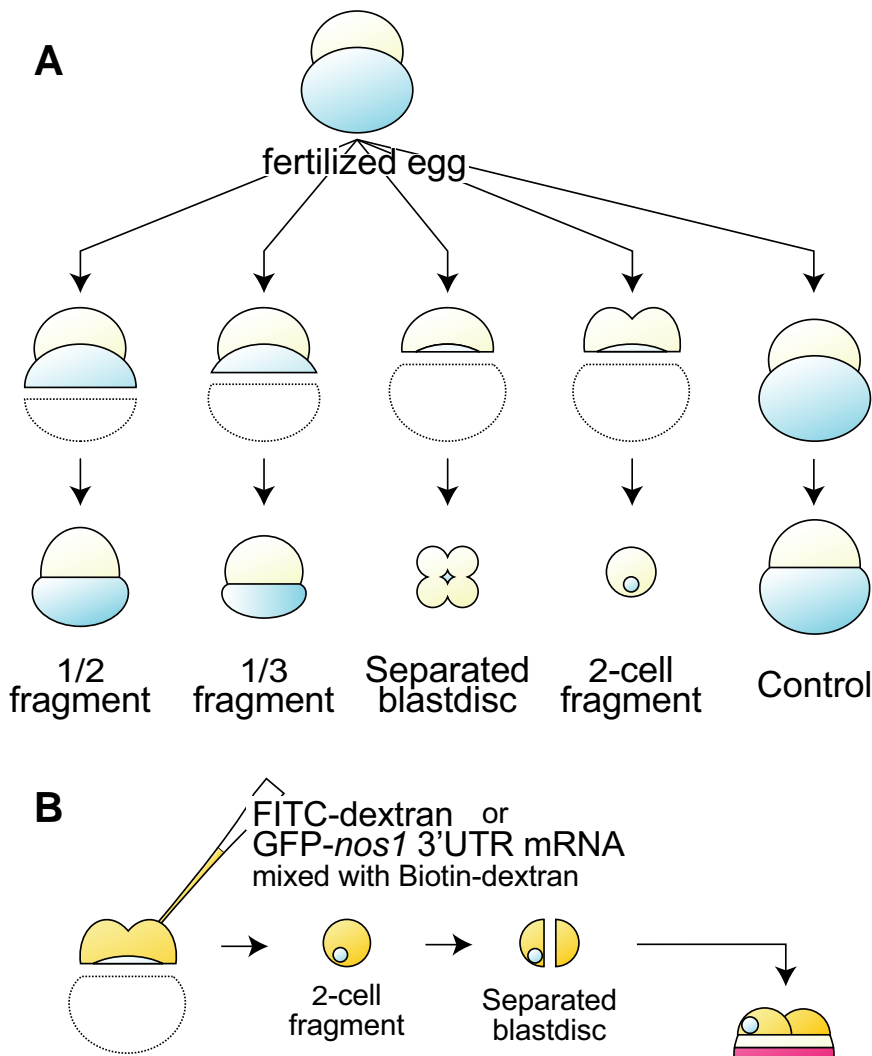

prospective mesodermal region
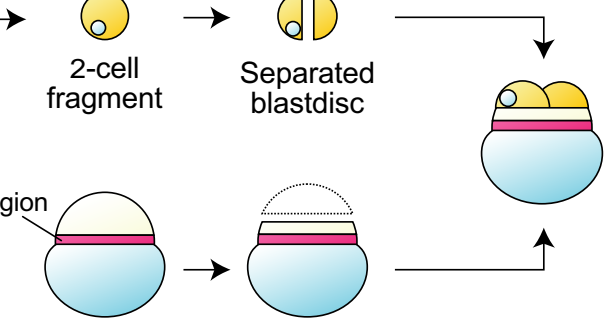

Normal embryo hypothesis. If the ectopic PGCs in the head migrate from the animal region, specifically the ectoderm region, it is expected that they differentiate without the mesoderm during epiboly. It is not known whether the ectopic PGCs maintain the potency to differentiate functional germ cells or not. In Xenopus, PGCs in the genital ridges could be formed from the cultured explants of germ plasm-bearing cells of 32-cell embryos when the explants were implanted into the endoderm cell mass of host neurulae (Ikenishi et al., 1984). Thus, the precursor of PGCs may autonomously differentiate into PGCs if transplanted in the proper region of the embryos. The properties of ectopic PGCs may offer further valuable information about PGC differentiation without a mesoderm.

In conclusion, the present study shows that small animal fragments contain sufficient factors for PGC differentiation. It also shows that PGCs differentiate without mesoderm induction. It remains unknown whether the aggregation at the terminal regions of early cleavage furrows satisfies the requirements for PGC differentiation without other signals from surrounding tissues. Further detailed studies are required to examine this issue.

\section{Materials and Methods}

\section{Fertilization and dechorionation}

Goldfish, Carassius auratus, have been reared in the Nanae Fresh Water Laboratory, Field Science Center for Northern Biosphere, Hokkaido University. Ovulation, artificial insemination and fertilization were performed as previously described (Yamaha and Yamazaki, 1993). Dechorionation was carried out before blastodisc formation using a method described by Yamaha etal. (1986), with slight modification. Dechorionated eggs were cultured in agar-coated petri-dish with Ringer's solution $(128 \mathrm{mM}$ $\mathrm{NaCl}, 2.8 \mathrm{mM} \mathrm{KCl}, 1.8 \mathrm{mM} \mathrm{CaCl}_{2}$ ) containing $1.6 \%$ albumen, $0.01 \%$ penicillin, $0.01 \%$ streptomycin and $0.01 \%$ kanamycin (culture Ringer's solution), until micro-surgical operation. Operated (see below) and control embryos were cultured in separate wells filled with culture Ringer's solution for 1 day and then transferred to wells filled with $1.8 \mathrm{mM} \mathrm{CaCl}_{2}, 1.8 \mathrm{mM}$ $\mathrm{MgCl} 2$ and the same antibiotics as in the culture Ringer's solution, at the same concentrations and incubated at $20^{\circ} \mathrm{C}$ for approximately 3 days. Thereafter, larvae were reared in tap water until 10 days post-fertilization (dpf).

The developmental schedule during the pre-gastrula stages in goldfish followed Yamaha et al. (1999) and after, Kajishima (1960).

\section{Microinjection}

In order to detect clonal progeny of graft cells in developing transplanted embryos, cytoplasm of the fertilized egg was labeled with biotin and

Fig. 9. Schematic representation of egg fragmentation and transplantation. (A) Egg fragmentation was performed horizontally at different levels perpendicular to the animal-vegetal axis at the 1- to 2-cell stage and embryos were allowed to develop. (B) Blastodiscs labeled with FITC-and biotin-dextran or GFP-nos1 3'UTR mRNA were fragmented at the 2-cell stage and allowed to develop as spherical embryos until the blastula stage. The spherical embryo was halved by a thin glass needle without breaking of inner yolk body and was then transplanted to the animal part of the blastoderm. 
fluorescein isothiocyabate (FITC). Biotin-dextran-fixable (5\%) (Sigma Chemical Co., St. Louis, MO, USA) and 5\% FITC-Dextran (Sigma) solution in 0.2M $\mathrm{KCl}$ was injected into the blastodisc at the one-cell stage, following the method described by Ho and Kane (1990).

In order to trace the PGCs from graft, donor PGCs were visualized with green fluorescent protein (GFP) fluorescence by injection of GFP-nos1 3'UTR mRNA following the method of Köprunner et al. (2001). The vector with GFP-nos1 3'UTR constructed following the method described by Hashimoto et al. (2004). Capped GFP-nos1 3'UTR mRNA was prepared by in vitro transcription using SP6 polymerase (mMessage mMachine; Ambion, Inc., Austin, TX, USA) according to the manufacturer's instructions. mRNA was suspended in $10 \mu \mathrm{M}$ HEPES buffer at a final concentration of $0.1 \mathrm{mg} / \mathrm{ml}$ and injected into 1-cell stage goldfish embryos with a glass capillary connected to a micro injector (Cell Tram, Eppendorf AG, Hamburg, Germany).

\section{Fragmentation of fertilized egg}

Horizontal fragmentation of eggs at the 1- and 2-cell stage was performed using a glass fiber needle (Wako Pure Chemical Industries, Ltd., Osaka, Japan) of approximately with about $20 \mu \mathrm{m}$ in diameter following the method described by Mizuno et al. (1997). Horizontal fragmentation was performed at the half or one-third level along the animal-vegetal axis at the 1-cell stage (Fig. 9A); the resultant fragments are hereafter referred to as $1 / 2$ and $1 / 3$ fragments, respectively. Cytoplasm of blastodiscs including small yolk was also fragmented at the 1- to 2-cell stage. The fragments at the 1-cell stage were allowed to develop and were fixed at the 4-cell stage for in situ hybridization. Fragments at the 2-cell stage are referred to as 2cell fragments. All procedures were performed in a glass dish coated with $1 \%$ agar and filled with culture Ringer's solution. The fragmented animal parts were allowed to develop in culture Ringer's solution at $20^{\circ} \mathrm{C}$ as described above.

\section{Whole mount in situ hybridization (WMISH)}

Embryos from dechorionated control and fragmented eggs were fixed at the 4-cell stage and at 15 or $25 \mathrm{~h}$ post-fertilization (hpf) with $4 \%$ paraformaldehyde in phosphate-buffered saline (PBS) at $4^{\circ} \mathrm{C}$ overnight. Fixed embryos were stored in $100 \%$ methanol at $-20^{\circ} \mathrm{C}$. Whole mount in situ hybridization (WMISH) to PGCs was performed as described by Jowett and Lettice (1994) with slight modifications using a $0.4 \mathrm{~Kb}$ fragment from the 3'UTR region of vas cDNA in zebrafish as a template. no tail ( $n t /)$ in zebrafish were used for the marker gene for mesoderm. For double in situ hybridization, RNA probes were labeled with UTP-11 digoxigenin for vas and with FITC for $n t$ t. After in vitro transcription, the RNA probe was purified using ProbeQuant G-50 Micro Columns (Amasham Pharmacia Biotech, Piscataway, NJ, USA). Proteinase $\mathrm{K}$ treatment was performed for $10 \mathrm{~min}$ at $10 \mu \mathrm{g} / \mathrm{ml}$ and the temperature of hybridization was $55^{\circ} \mathrm{C}$ (Otani et al., 2002).

After WMISH staining, embryos were cleared in $50 \%$ glycerol and mounted on the dimple of an agar plate. Photographs were taken using an Olympus CAMEDIA imaging system DS3030U equipped with an SZX-12 stereomicroscope.

\section{Graft transplantation}

In order to elucidate the differentiation of PGCs, spherical embryos from egg fragments were transplanted to normal embryo (Fig. 9B). Blastodiscs of the labeled egg were bisected at the 2-cell stage and allowed to develop as spherical embryos while control embryo developed to midblastula ( $6 \mathrm{hpf}$ ). The spherical embryos were halved by the glass fiber needle, without breaking the inner yolk body and transplanted to the animal part of the host blastodisc, where the enveloping layer cells at the animal part of blastoderm had been removed. Resultant chimeric embryos were cultured by the standard procedure. Blastodiscs of the embryo injected with tracer dye or GFP-nos1 3'UTR mRNA were bisected at the 1-cell stage (described below), allowed to develop at $20^{\circ} \mathrm{C}$ for 6 to $8 \mathrm{hpf}$ in $1 \mathrm{st}$ culture Ringer's solution and transplanted onto the animal part of the untreated embryos without mRNA injection (Fig. 9B). Transplanted embryos were cultured under previously described condition and examined under a fluorescence stereo-scopic microscope (Olympus SZX12-RFL).

\section{Histology}

For histological observation of PGCs, embryos were fixed with Bouin's fixative over $2 \mathrm{~h}$, dehydrated in a butyl alcohol series and embedded in a paraffin block. Serial sections were cut at $8 \mu$ m and stained with haematoxylin and eosin. In embryos transplanted with biotin-labeled cells, the labeled cells were histologically detected using a Histofine SAB-PO(M) kit (Nichirei Co., Ltd., Tokyo, Japan). Sections of which paraffin was removed with prewarmed xylol were hydrated with alcohol series and soaked with $0.1 \mathrm{M}$ PBS. The sections were reacted with peroxidase-conjugated strepto avidin (Nichirei) for $30 \mathrm{~min}$, rinsed with PBS and colored with diaminobenzidine (DAB) and stained faintly with eosin. Photographs were taken using an Olympus CAMEDIA C3040 equipped with a BH-2 microscope. Labeledand unlabeled-PGCs were detected by histological characters according to Kazama-Wakabayashi et al. (1999).

\section{Acknowledgments}

We thank Mr. S. Kimura, Ms. C. Nishida, Ms. M. Takagi and members of Nanae Fresh Water Laboratory, Field Science Center for Northern Biosphere, Hokkaido University for their help. We also thank the members of the laboratory of Breeding Sciences, Graduate School of Fisheries Sciences, Hokkaido University for their useful discussion. This study was supported by the COE program for graduate school of Fisheries Science of Hokkaido University and by the COE program for Faculty of Agriculture of Kinki University and in part by Grants-in-Aid from the Ministry of Education, Science and Culture of Japan (No. 12460081, 14360105) and the Akiyama Foundation in 1999 to E. Yamaha and that in 2000 to K. Arai.

\section{References}

AGIUS, E., OELGESCHLAGER, M., WESSELY, O., KEMP C. and DE ROBERTIS E.M. (2000) Endodermal Nodal-related signals and mesoderm induction in Xenopus. Development 127:173-1183

BRAAT, A.K., ZANDBERGEN, T., VAN DE WATER, S., GOOS, H.J.T.H. and ZIVKOVIC, D. (1999) Characterization of zebrafish primordial germ cells: morphology and early distribution of vas RNA. Dev Dynamics 216: 153-167

COFFMAN, C.R. (2003) Cell migration and programmed cell death of Drosophila germ cells. Ann N Y Acad Sci 995: 117-126.

HASHIMOTO, Y., MAEGAWA, S., NAGAI, T., YAMAHA, E., SUZUKI, H., YASUDA, K. and INOUE, K. (2004) Requirement of localized maternal factors for zebrafish germ cell formation. Dev Biol 268: 152-161.

HAYASHI, Y., HAYASHI, M. and KOBAYASHI, S. (2004) Nanos suppresses somatic cell fate in Drosophila germline. Proc. Natl. Acad. Sci. USA. 101, 10338-10342.

HOFFMANN, R. and VALENCIA, A. (2004) A gene network for navigating the literature. Nature Genetics 36: 664.

HO, R.K. and KANE, D.A. (1990) Cell-autonomous action of zebrafish spt-1 mutation in specific mesodermal precursors. Nature 348: 728-730.

IKENISHI, K., OKUDA, T. and NAKAZATO, S. (1984) Differentiation of presumptive primordial germ cell (pPGC)-like cells in explants into PGCs in experimental tadpoles. Dev. Biol 103, 258-262.

JAGLARZ, M.K. and HOWARD, K.R. (1994) Primordial germ cell migration in Drosophila melanogaster is controlled by somatic tissue. Development 120: 8389.

JOLY, J.-S., JOLY, C., SCHULTE-MERKER S., Boulekbache, H. and Condamine, H. (1993) The ventral and posterior expression of the zebrafish homeobox gene eve1 is perturbed in dorsalized and mutant embryos. Development 119: 1261-1275.

JOWETT, T. and LETTICE, L. (1994) Whole-mount in situ hybridizations on zebrafish probes. Trend Genet 10: 73-74.

KAJISHIMA, T. (1960) The normal developmental stage of the goldfish, Carassius auratus. Japan J Ichthyol 8: 20-28. (in Japanese with English summary).

KAZAMA-WAKABAYASHI, M., YAMAHA, E., YAMAZAKI F. (1999) The elimination 
and duplication of lower part of blastoderm effects on the number of primordial germ cells in goldfish. Fisheries Science 65:577-584.

KÖPRUNNER, M., THISSE, C., THISSE, B. and RAZ, E. (2001) A zebrafish nanosrelated gene is essential for the development of primordial germ cells. Genes Dev 15: 2877-2885.

KOSHIDA, S., SHINYA, M., MIZUNO, T., KUROIWA, A. and TAKEDA, H. (1998) Initial anteroposterior pattern of the zebrafish central nervous system is determined by differential competence of the epiblast. Development 125:1957-1966.

LAWSON, K. A., DUNN, N. R., ROELEN, B. A., ZEINSTRA, L. M., DAVIS, A. M., WRIGHT, C. V., KORVING, J. P. and HOGAN, B. L. (1999) Bmp4 is required for the generation of primordial germ cells in the mouse embryo. Genes Dev 13: 424436.

MIZUNO, T., YAMAHA, E., KUROIWA, A. and TAKEDA, H. (1999) Removal of vegetal yolk causes dorsal deficiencies and impairs dorsal-inducing ability of the yolk cell in zebrafish. Mech Dev 81: 35-47.

MIZUNO, T., YAMAHA, E., WAKAHARA, M., KUROIWA, A. and TAKEDA, H. (1996) Mesoderm induction in zebrafish. Nature, 383: 131-132.

MIZUNO, T., YAMAHA, E. and YAMAZAKI, F. (1997) Localized axis determinant in the early cleavage embryo of the goldfish, Carassius auratus. Dev Genes Evol 206: 389-396.

NIEUWKOOP, P. D. and STASURYA, L. A. (1976) Primordial germ cells in the chordates. Embryogenesis and Phylogenesis. Cambridge Univ Press, Cambridge pp187.

OPPENHEIMER, J.M. (1936) The development of isolated blastoderms of Fundu/us heteroclitus. J. Exp. Zool. 72: 247-269.

OTANI, S., MAEGAWA, S., INOUE, K., ARAI, K. and YAMAHA, E. (2002) The germ cell lineage identified by vas-mRNA during the embryogenesis in goldfish. Zool Sci 19: 519-526.

PELEGURI, F. (2003) Maternal factors in zebrafish development. Dev. Dyn. 288:535554

RODAWAY, A., TAKEDA, H., KOSHIDA, S., BROADBENT, J., PRICE, B., SMITH, J. C., PATIENT, R. and HOLDER, N. (1999) Induction of the mesendoderm in the zebrafish germ ring by yolk cell-derived TGF- $\beta$ family signals and discrimination of mesoderm and endoderm by FGF. Development 126: 3067-3078.

SAITO, T., OTANI, S., SUZUKI, T., NAKATSUJI, T., ARAI, K. and YAMAHA, E. (2004) The germ line lineage in ukigori, Gymnogobius species (Teleostei; Gobiidae) during embryonic development. Int J Dev Biol 48: 1079-1085.

SANO, H., MUKAI, M. and KOBAYASHI, S. (2004) Maternal Nanos and Pumilio regulate zygotic vasa expression autonomously in the germline progenitors of Drosophila embryos. Develop. Growth \& Differ. 43, 545-552, 2001.

SCHULTE-MERKER, S., HO, R.K., HERRMANN, B.G. and NUSSLEI-VOLHARD, C.
(1992) The protein product of the zebrafish homologue of the mouse $T$ gene is expressed in nuclei of the germ ring and the notochord of the early embryo. Development, 116: 1021-1032.

STACHEL, S. E., GRUNWALD, D. J. and MYERS, P. Z. (1993) Lithium perturbation and goosecoid expression identify a dorsal specification pathway in the pregastrula zebrafish. Development 117: 1261-1274.

STRAHLE, U. and JESUTHASAN, S. (1993) Ultraviolet irradiation impairs epiboly in zebrafish embryos: evidence for a microtuble-dependent mechanism of epiboly. Development 119: 909-919.

STANZ-GAIANO, M. and LEHAMAN, R. (2001) Moving towards the next generation. Mech Dev 105: 5-18.

SUTASURYA, L. A. and NIEUWKOOP, P. D. (1974) The induction the primordial germ cells in the urodeles. Wilhelm Roux's Archiv 175: 199-220.

TIMMERMANS, L. P. M. (1996) Origin and differentiation of primordial germ cells in vertebrates especially fishes. Netherlands J Zool 46: 147-162.

TOYAMA, R., O'CONNEL, M. L., WRIGHT, C. V. E., KUEHN, M. R. and DAWID, I. B. (1995) noda/induces ectopic goosecoid and lim1 expression and axis duplication in zebrafish. Development 121: 383-391.

TUNG, T.C., CHANG, C.Y. and TUNG, Y.F.Y. (1945) Experiments on the developmental potencies of blastoderms and fragments of teleostean eggs separated latitudinally. Proc. Zool. Soc. 115: 175-188.

WEIDINGER, G., WOLKE, U., KOPRUNNER, M., KLINGER, M. and RAZ, E. (1999) Identification of tissues and patterning events required for distinct steps in early migration of zebrafish primordial germ cells. Development 126: 5295-5307.

WOO, K. and FRASER, S. E. (1997) Specification of the zebrafish nervous system by nonaxial signals. Science 277: 254-257.

YAMAHA, E., MIZUNO, T., MATSUSHITA, K. and HASEBE, Y. (1999) Developmental staging in goldfish during the pre-gastrula stage. Fisheries SCi 65: 709-717.

YAMAHA, E., USUI, K., ONOZATO, H. and HAMADA, K. (1986) A method for dechorionation in goldfish, Carassius auratus. Fisheries Sci 52: 1929-1934.

YAMAHA, E. and YAMAZAKI, F. (1993) Electrically fused-egg induction and its development in the goldfish Carassius auratus. Int J Dev Biol 37: 291-298.

YOON, C., KAWAKAMI, K. and HOPKINS, N. (1997) Zebrafish vas homologue RNA is localized to the cleavage planes of 2-and 4-cell-stage embryos and expressed in the primordial germ cells. Development 124: 3157-3166.

Received: January 2005

Reviewed by Referees: January 2005

Modified by Authors and Accepted for Publication: April 2005

Edited by: Makoto Asashima 